\title{
III. AGUA: ASUNTO DE SEGURIDAD NACIONAL E IMPORTANCIA DE LA PARTICIPACIÓN CIUDADANA EN SU GESTIÓN: LA EXPERIENCIA DE SONORA ENTIDAD FEDERATIVA DE MÉXICO.
}

\author{
Por Dra. Adria Velia GONZALEZ BELTRONES. \\ Profesora e Investigadora de la Universidad de Sonora \\ adriag@sociales.uson.mx
}

Resumen

En México, el significado del agua, ha sufrido cambios dramáticos durante las últimas seis décadas; a nivel mundial, puede asegurarse a partir de las reuniones de Estocolmo (1972) y Río de Janeiro (1992) y se relaciona con el crecimiento de la población - entre 1950 y 2000 la población mundial se triplicó-, pasando de 2500 a 6000 millones. En México, aumentó de 25 a 100 millones de personas. El agua, recurso natural integral de los ecosistemas en su movimiento natural en las zonas por donde fluye, si bien no reconoce fronteras geopolíticas su importancia en el desarrollo social y económico de las naciones define una serie de interacciones de tal complejidad que demandan conocimiento para su manejo integral. Este trabajo, pretende destacar la importancia de la apertura de los espacios de participación ciudadana en el manejo sustentable del recurso hídrico, su consolidación a través de la expedición urgente de los reglamentos y manuales que señala la propia Ley de Aguas Nacionales para definir los límites de la descentralización, convenir con claridad las responsabilidades relacionadas con la gestión del agua y recursos presupuestales asignables al efecto y poder exigir de las autoridades transparencia de la eficacia en su manejo.

Introducción

El orden jurídico mexicano en el que se comprende la administración del agua ha evolucionado con las propias necesidades que esta actividad plantea desde normas simples religiosas en la época prehispánica según señala Lanz Cárdenas (1992) cuando afirma que se pretende sostener que en la época del México prehispánico no había regulación de las aguas interiores, cuando la historia de nuestras culturas autóctonas (aztecas, otomíes, olmecas, mayas, totonacas), indica que en cada una de estas civilizaciones las aguas estaban divinizadas, es decir, al estar relacionadas con la divinidad, consecuentemente se manejaban por las teocracias sacerdotales a nivel de concesiones, de dotaciones o de usos; lo cierto es que las aguas en México siempre han sido reguladas por diversas legislaciones según lo relatan -además de Lanz Cárdenas- de manera cronológica diversos autores, entre ellos, Serra Rojas(2001) que a diferencia de lo que opina Acosta Romero (2004)desde la época precortesiana surgieron las primeras normas de derecho consuetudinario sobre el agua con el propósito de evitar querellas que se presentaban con motivo de su aprovechamiento y asegurar que esta no faltara a los grupos indígenas; hasta la situación presente en la que se regula por un complejo andamiaje de ordenamientos que comprenden desde su Constitución Política y los tratados y convenciones internacionales ratificados, así como las leyes reglamentarias relativas y sus reglamentos; decretos, acuerdos y actos ejecutivos presidenciales; normas oficiales mexicanas y prácticas recomendadas por organismos certificadores; convenios, reglas de carácter general, circulares, manuales de organización; actos y resoluciones administrativas concretos e individualizados; actos, resoluciones y sentencias judiciales; jurisprudencia y normas y actos jurídicos locales relativos.

El significado del agua, ciertamente ha sufrido cambios dramáticos en nuestro país durante las últimas seis décadas. 'Mientras que en 1947 se sostenía que era obligación del Estado encabezar el aprovechamiento científico del agua para hacer de ella un bastión del progreso nacional, en la década de los noventa se decía, en cambio, que el Estado debía atender una extrema crisis hidráulica marcada por la escasez, la contaminación y el derroche. Mientras que en 1950 reinaba el optimismo de los ingenieros- 
políticos las grandes posibilidades que según ellos abría al país la expansión de los usos del agua, a principios del Siglo XXI prevalece un pesimismo que llevó a declarar el agua como asunto de seguridad nacional. Del agua que había que dominar y controlar se pasó al agua que había que cuidar" (Aguilar Aboites 2000:89). Resulta obvio señalar, que dicho cambio no es exclusivo de nuestro país, pues a nivel mundial puede asegurarse con bastante precisión a partir de las reuniones de Estocolmo (1972) y de Río de Janeiro (1992).Ciertamente, este cambio de significado se relaciona con el crecimiento de la población ya que entre 1950 y 2000 la población mundial se triplicó, pasando de 2500 a 6000 millones. En México se aumentó de 25 a 100 millones de personas.

\section{Objetivo general}

A partir de la experiencia de Sonora (entidad federativa del norte de México) en este trabajo se pretende: Destacar la importancia de a) incluir en la legislación vigente, mecanismos adecuados de participación corresponsable de los actores involucrados, en la gestión del agua, a efecto de que b)se garantice su sustentabilidad por cuenca y con ello: c) potenciar su actuación de manera eficiente y corresponsable, exigir de las autoridades transparencia de la eficacia en su manejo y contribuir eficazmente a la supervivencia física de la persona individual y de la sociedad.

Ahora bien, si partimos de las siguientes dos concepciones sobre "seguridad pública":

1) “Actividad esencial del Estado sin cuya realización sobreviene el caos y el Estado tiende a su desaparición"

2) "Preservación del orden público, de la integridad, de los bienes y derechos de las personas"; y las desligamos de a) la prevención y la investigación de los delitos y la presentación de la justicia ante los órganos jurisdiccionales así como b) del órgano a quien se encomienda su preservación(corporaciones policiales, fuerzas militares de tierra, mar y aire; el ejército, la armada y la aviación militar de un país), resulta más comprensible declarar el agua como asunto de seguridad nacional y en el contexto global como asunto de seguridad mundial.

\section{Antecedentes}

La escasez de agua dulce es uno de los siete problemas ambientales fundamentales presentados en el Informe del Programa de Naciones Unidas para el Medio Ambiente (PNUMA) ${ }^{17}$, denominado "Perspectivas del Medio Ambiente Mundial" ${ }^{18}$ En una encuesta realizada a 200 científicos lo señalan, junto al cambio climático, como el principal problema del nuevo siglo. De forma sencilla se puede decir que estamos alcanzando el límite de extraer agua dulce de la superficie terrestre, pero el consumo no deja de aumentar.

\section{Desafíos}

Cada día aumenta la necesidad de lograr el equilibrio hidrológico que asegure el abasto suficiente de agua a la población, y ello solo se alcanzará armonizando la disponibilidad natural con las

\footnotetext{
${ }^{17}$ (UNEP por sus siglas en inglés) con sede en Nairobi, Kenia, es un programa de las Naciones Unidas que coordina las actividades relacionadas con el medio ambiente, asistiendo a los países en la implementación de políticas medioambientales adecuadas así como a fomentar el desarrollo sostenible. Fue creado por recomendación de la Conferencia de las Naciones Unidas sobre el Desarrollo Humanos (Estocolmo - 1972).

${ }^{18}$ El estudio se ha realizado por 24 organismos y entidades de las Naciones Unidas que integran ONU-Agua, y por el encargado de coordinar su elaboración, el Programa Mundial de Evaluación de los Recursos Hídricos (WWAP). http://www.ecoportal.net/content/view/full/84833
} 
extracciones del recurso mediante el uso eficiente del agua y contrarrestando el efecto que el cambio climático tendrá sobre el ciclo hidrológico y la disponibilidad de agua dulce.

Al respecto y dada la fuerte demanda actual de agua en constante aumento, el informe de la UNESCO "El agua en un mundo en cambio", presenta la evaluación global más completa de los recursos de agua dulce del planeta realizada hasta ahora. Y pone de relieve el papel que este imprescindible líquido desempeña en el desarrollo y el crecimiento económico.

El informe, que se publica cada tres años, afirma que:

“Por la creciente escasez de agua, un gobierno adecuado es imprescindible para su gestión. La lucha contra la pobreza depende también de nuestra capacidad para invertir en los recursos hídricos", ha declarado el Director General de la UNESCO, Koichiro Matsura. Algunos países "están llegando al límite de la explotación de sus recursos hídricos".A esto se añaden los efectos del cambio climático que agravarán la situación."

Por ello, los expertos consideran que la cuestión del agua podría llegar a politizarse debido a "las rivalidades emergentes entre diferentes países, diferentes sectores de actividad, y entre zonas rurales y urbanas".

El precitado informe alerta al señalar que:

“En España al igual que en otros países como México, la mayor preocupación es el uso del agua para la irrigación de los campos agrícolas para posteriormente exportar frutas y otros productos, entre ellos el aceite. Este uso se verá cada vez más cuestionado por el cambio climático, que limitará la disponibilidad de agua. Ante este panorama, España sólo reutiliza el 1,1\% de las aguas procedentes del drenaje del agua en la agricultura y destina parte a la desalinización para su uso. En el resto del mundo, los problemas son mayores. Ante la inexistencia de servicios básicos adecuados relacionados con el agua (agua potable segura, saneamiento y producción de alimentos) en muchas regiones del mundo-- y si estas tendencias persisten--, se prevé que en 2030 unos 5.000 millones de personas, es decir, el $67 \%$ de la población mundial, seguirán desprovistos de servicios adecuados de saneamiento."

Según el informe, los progresos en materia de servicios básicos de saneamiento son:

"Insuficientes para alcanzar los Objetivos de Desarrollo del Milenio (ODM), que indican que en 2015 más del 90\% de la población mundial utilizará fuentes mejores de agua potable.

África Subsahariana cuenta todavía con $\mathbf{3 4 0}$ millones de personas sin acceso a agua potable segura, y $\mathbf{5 0 0}$ millones de personas carecen de acceso a servicios de saneamiento adecuados. Esta cifra coincide con las personas más pobres, que viven con menos de 1,25 dólares al día.

La desigual situación mundial repercute en la salud de las poblaciones. El $80 \%$ de las enfermedades que azotan a los países en vía de desarrollo están relacionadas con el agua y causan la muerte prematura de unos tres millones de personas. La diarrea, por ejemplo, mata cada día en el mundo a unos 5.000 niños, uno cada 17 segundos."

El Informe señala que el $10 \%$ de las enfermedades de todo el mundo se podrían evitar con la mejora del abastecimiento de agua, los servicios de saneamiento, la higiene y la gestión de los recursos hídricos. 
Aumento de la demanda del agua

Asimismo, el informe añade que:

"En los últimos 50 años, las extracciones de agua dulce se han triplicado y la superficie de tierras de regadío se han duplicado debido al crecimiento demográfico. La demanda anual de agua dulce será de $\mathbf{6 4 . 0 0 0}$ millones de metros cúbicos."

En este sentido, la agricultura es:

"El sector que más agua consume representando el $70 \%$ del consumo total de agua, mientras que el agua destinada a usos industriales y la dedicada a usos domésticos representan un $20 \%$ y un $10 \%$, respectivamente. Si no se mejora la productividad del agua destinada a usos agrícolas, es probable que su demanda a escala mundial aumente entre un $70 \%$ y un $90 \%$ en $2050 . "$

También generarán un incremento del uso del agua:

"El aumento de la producción de alimentos (sobre todo de carne y productos lácteos), de biocombustibles, y en general de energía (cuya demanda mundial se prevé que aumente en un 55\% hasta 2030)."

Según los autores del informe, a pesar de las posibilidades que ofrecen los biocarburantes para disminuir la dependencia de los combustibles fósiles, es probable que:

"Acaben ejerciendo una presión desmesurada sobre la biodiversidad y el medio ambiente, sobre todo, por los recursos y la tecnología que se utilizan actualmente para producirlos."

Ahora bien, de acuerdo al rol del cambio climático en las corrientes migratorias, en 2030, el 47\% de la población mundial vivirá en zonas donde la presión ejercida sobre los recursos hídricos será muy intensa. En 2020, entre 75 y 250 millones de habitantes de África sufrirán las consecuencias del incremento de las presiones ejercidas sobre los recursos hídricos a causa de la creciente desertificación del continente y su explotación por parte de los países industrializados. La escasez de agua en algunas regiones áridas y semiáridas del planeta podría tener importantes repercusiones en las corrientes migratorias. Según las previsiones, el número de personas que podrían verse desplazadas a causa de esa escasez oscilaría entre 24 y 700 millones.

Planteamiento del problema

¿Es solución, la mejor gestión del agua? Según el multicitado informe, para minimizar las pérdidas de agua, mejorar su gestión y reducir su demanda, existen ya políticas públicas. Muchos países han adoptado leyes para proteger sus recursos hídricos y administrarlos con prudencia. Sin embargo, la UNESCO afirma que estas medidas todavía no han surtido efectos palpables porque, con frecuencia, se limitan exclusivamente al sector del agua, y las decisiones clave que le afectan se toman al margen del mismo. $^{19}$

\footnotetext{
${ }^{19}$ En el caso de la cuenca mediterránea, las redes urbanas de abastecimiento y los sistemas de riego agrícolas son muy ineficaces, debido a las importantes pérdidas de agua ocasionadas por los escapes. Se ha calculado que se desperdicia el $25 \%$ del agua en las zonas urbanas y el $20 \%$ en las acequias.

Además, aunque el tratamiento de las aguas residuales aumenta la disponibilidad de agua, como es el caso de España, su uso sigue siendo limitado para uso agrícola. Otro procedimiento es la desalinización del agua del mar para usarla como agua potable, o destinarla a usos industriales.
} 
En el caso que nos ocupa, la falta de ejercicio de las facultades de comprobación de la (CNA) en la actualidad (y de sus homólogas en distintas épocas) del cumplimiento de las obligaciones a que se refiere la Ley de Aguas Nacionales y otros ordenamientos por parte de asignatarios y concesionarios de los derechos de Agua de la cuenca del Río Sonora, ha generado la sobre explotación y agotamiento del acuífero de la costa de Hermosillo,

Justificación del tema

En este contexto, los autores del informe afirman que para que las medidas sean efectivas, es imprescindible involucrar en ellas a responsables (participación) "de muchos otros sectores como la agricultura, la energía, el comercio y la banca, porque ejercen una influencia decisiva en la gestión de los recursos hídricos".

El informe destaca también la importancia de la cooperación entre los gobiernos, las empresas privadas y las organizaciones de la sociedad civil (gobernanza) en la gestión del agua. Y, es en este punto donde se inserta el contenido del presente trabajo por lo que resulta necesario realizar las siguientes:

\section{Precisiones}

1) En México, un país rico en recursos naturales se obtiene el agua que consume la población de diversas fuentes tales como ríos, arroyos y acuíferos del subsuelo. Estos acuíferos se recargan de forma natural en época de lluvias. Sin embargo, la duración de la época de lluvias es en promedio de cuatro meses lo que favorece una escasa captación. Si además se considera que del total de agua captada por lluvias, aproximadamente el $70 \%$ se evapora, la desproporción que existe entre la cantidad de agua que se capta por escurrimiento y las extensiones territoriales que comprenden hace que la disponibilidad del agua sea cada vez menor.

Bajo esta perspectiva México enfrenta actualmente graves problemas de disponibilidad, desperdicio y contaminación de agua. Parte de esta problemática, se enfrenta con la construcción de la infraestructura hidráulica que permite satisfacer de agua a los diferentes sectores de la población: el agrícola, el industrial, el doméstico y de servicios y para la generación de energía eléctrica entre otros.

2) Además, cabe recordar que existen diferencias territoriales importantes que son desfavorables:

a) En el norte del territorio nacional, el agua de lluvia que se capta por escurrimiento es únicamente el $4 \%$ mientras que en el sureste y las zonas costeras se logra captar el $50 \%$ del escurrimiento.

c) En la zona sur del país, donde se localizan las regiones húmedas, las presas tienen como función almacenar el agua para la generación de la energía eléctrica y el control de avenidas.

d) Por el contrario en la zona norte del país, al estar constituida por regiones áridas, las presas tienen la función de captar el agua que se utilizará en la actividad agrícola

3) En México, la gestión del agua se encuentra centralizada en la Comisión Nacional del Agua (CNA), a pesar de lo que sostiene el discurso oficial en el que se da por sentado que ha tenido lugar un proceso de descentralización $^{20}$ de la gestión del agua, a través del cual se ha fortalecido la capacidad

\footnotetext{
${ }^{20}$ En este sentido coincidimos con el estudioso de este tema Juan Jaime Sánchez Meza al señalar que dicho discurso ha pretendido materializarse, entre otros instrumentos, en una amplísima reforma legislativa que, por primera vez desde 1888 -año en que tuvo lugar Revista Jurídica del Departamento de Derecho Academia de Derecho Administrativo Tercera Época. Año 2. No 2. Vol. 1.Enero-Junio 2010
} 
institucional de los gobiernos locales, así como de los usuarios, vía los consejos de cuenca. En este contexto cabe resaltar:

4) La reforma legislativa de 2004:

a) Ha propuesto una reestructuración administrativa de la entidad centralizadora, esto es la Comisión Nacional del Agua (CNA), dando lugar a la conversión de lo que fueron las Gerencias Regionales, convirtiéndolas en Organismos de Cuenca, además de que los consejos de cuenca fueron, también, objeto de una importante reestructuración. En los hechos:

b) Sólo otorgó al Ejecutivo Federal la atribución de "favorecer" la descentralización, "fomentar" la participación de los usuarios, así como declarar de "interés público" la descentralización y mejoramiento de la gestión de los recursos hídricos "con la participación de los estados, del Distrito Federal y de los municipios". Pero no creó los instrumentos, mecanismos, instancias, procesos y condiciones para que ello fuera posible, y en contrapartida

c) Generó una reforma administrativa que, por una parte, no sólo dejó intactas las atribuciones que, con carácter exclusivo, la Ley ya le confería a la CNA, sino que las incrementó en forma cualitativa y cuantitativa, al mismo tiempo que consolidó su presencia regional mediante el fortalecimiento de las capacidades de los Organismos de Cuenca, a los que por una parte fortalece y, al mismo tiempo, sujeta. Es decir, por un lado concede a estas instancias un conjunto de atribuciones que hasta entonces no ejercían las Gerencias Regionales y, por la otra, les impone una clara subordinación jurídica a las decisiones centrales, como típicamente corresponde a los entes que gozan de un estatus desconcentrado, por lo que,

d) Para efectos prácticos, lejos de favorecer la política de descentralización que explícitamente había comprometido el Ejecutivo Federal, lo que en los hechos consiguió el legislador federal fue fortalecer aún más, refinándolo, el centralismo de la gestión del agua en el país.

De otra parte:

5) El tema relacionado con los niveles mas adecuados para la gestión del agua es más complicado que el de cualquier otro recurso de naturaleza semejante, dado que aquélla no reconoce límites geográficos ni político-administrativos, lo que revela la complejidad de las decisiones que plantean la necesidad de conciliar la gestión a través de las unidades territoriales más adecuadas para ello, esto es, las cuencas hidrográficas, y la urgencia de redistribuir entre niveles de gobierno las facultades de decisión que permitan mejorar la gestión del recurso. Ante ello, cabe precisar que:

6) La reforma legislativa mexicana (2004) evadió el tema cuya complejidad es preciso reconocer, pero cuyas aristas ofrecen alternativas de tratamiento, a partir de la experiencia latinoamericana - incluso en países con gobiernos federales como el nuestro- y del propio ejercicio nacional, como ejemplarmente lo ofrece la legislación en materia ambiental.

7) La Ley General del Equilibrio Ecológico y la Protección al Ambiente, que data de 1988, que experimentó importantes reformas en el mes de diciembre de 2001, es un buen ejemplo de cómo avanzar en la identificación de las particularidades y en la gradualidad de las decisiones. El artículo 11 de dicha Ley enlista de manera expresa un amplio listado de facultades concretas, reservadas al nivel central de gobierno, que por la vía de convenios o acuerdos de coordinación, son susceptibles de ser asumidas por los gobiernos estatales o municipales, por ejemplo, en materia de administración y vigilancia de áreas naturales protegidas; control de residuos peligrosos; evaluación de impacto ambiental; preservación de

la reforma constitucional que confirió el primer conjunto de atribuciones al gobierno federal en la materia- ha contemplado expresamente la descentralización en varios de sus apartados.

Revista Jurídica del Departamento de Derecho Academia de Derecho Administrativo

Tercera Época. Año 2. No 2. Vol. 1.Enero-Junio 2010 
suelo, flora y fauna silvestre y los recursos forestales, entre otros. El proceso se fortalece en la medida que contempla la transferencia de infraestructura, equipamiento y material especializado, asesoría técnica, capacitación, transferencia de personal, recursos presupuestales y gestión para el otorgamiento de créditos.

Sin embargo, más allá de la expresión temática acotada, que el legislador federal otorga al compromiso del gobierno central:

8) La reforma legislativa de 2004 es especialmente relevante porque:

a) deja en manos de los gobiernos locales la asunción de la iniciativa que desata el proceso de descentralización, lo que

b) nos coloca frente a un ángulo del fenómeno descentralizador pocas veces evaluado: 1) la aparente escasez de iniciativas locales que pugnen por la transferencia de facultades ejecutivas del centro a las regiones y que superen los tradicionales reclamos episódicos contra el centralismo y2) sus efectos.

Determinar la participación y grado de responsabilidad que los niveles local y central deben asumir en el replanteamiento del reparto de facultades, implica, mucho menos que otras condiciones como la definición de los órganos que llevarán a cabo las acciones o el establecimiento preciso del objeto, la resuelta voluntad política de ambos en favor de la descentralización.

9) En el caso de la gestión del agua, el fenómeno del centralismo se alimenta no sólo de la voluntad del gobierno federal de mantener el status quo, sino de la más que evidente apatía de los gobiernos locales. ${ }^{21}$ En este tenor y no obstante las limitaciones legales y constitucionales a que se enfrenta la gestión descentralizada del agua en México,.

10) Algunas disposiciones aisladas de la Constitución Política de los Estados Unidos Mexicanos, ofrecen en forma genérica la posibilidad de que los gobiernos estatales asuman, por la vía de los convenios de coordinación, el ejercicio de determinadas funciones que corresponden a la esfera federal de atribuciones.

11) Si bien dichos convenios son la ruta que el gobierno federal ha encontrado para lograr la participación de los gobiernos estatales en torno de programas de interés propio de la federación, al mismo tiempo que han hecho posible la conformación de mezclas de recursos presupuestales de uno y otro orden de gobierno, nada impide que ese marco de actuación pueda, a su vez, ser formulado a iniciativa ya no del gobierno federal, sino de algún gobierno estatal.

12) La norma constitucional aplicable se encuentra contenida en el Artículo 116, fracción VII, de la Carta Magna, que señala que la Federación y los Estados, en los términos de ley, "podrán convenir la asunción por parte de éstos del ejercicio de sus funciones, la ejecución y operación de obras y la prestación de servicios públicos, cuando el desarrollo económico y social lo haga necesario".

\footnotetext{
${ }^{21}$ Aunque no fue posible confirmarlo, uno de los más importantes asesores de la Comisión de Recursos Hidráulicos del Senado de la República, que operó como cámara de origen en el proyecto legislativo que concluyó con la reforma a la Ley de Aguas Nacionales, señaló que en el proceso de consulta informal, varios gobernadores de los estados fueron consultados sobre el tema y, salvo uno que aceptaba condicionadamente la posibilidad de asumir determinadas atribuciones en materia de gestión del agua, el resto se rehusó a considerar esa posibilidad. 


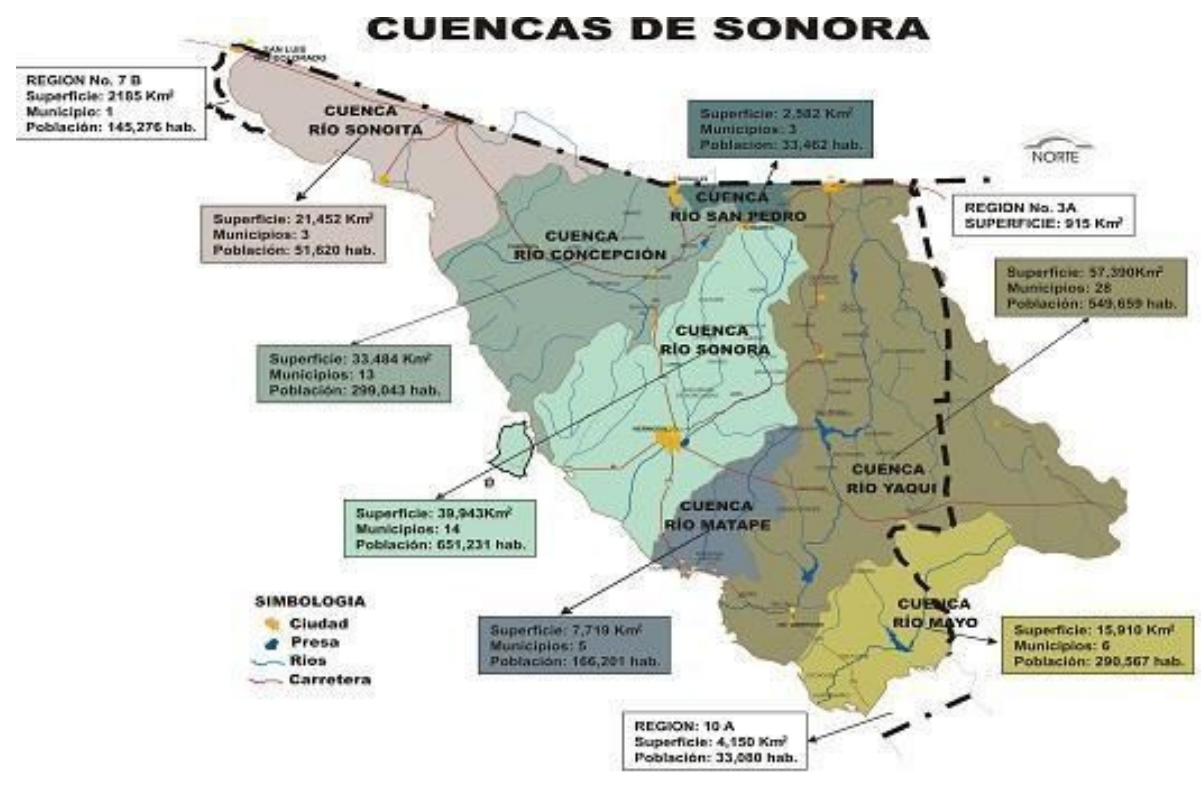

La Cuenca del Río Sonora, la mas grande de las 10 que se comprenden en el estado, cuenta con una superficie de $39,943 \mathrm{~km} 2$ y 14 municipios.

13) El gobierno del estado de Sonora a través de la Comisión Estatal del Agua, elaboró (2007) un proyecto de Convenio de Coordinación ${ }^{22}$ para la descentralización de la gestión del agua, cuyo objeto fue el de establecer las bases, criterios, condiciones y mecanismos a efecto de que aquel asuma un conjunto de funciones y atribuciones respecto de actos de carácter administrativo y fiscal, aplicables en la Cuenca del Río Sonora ${ }^{23}$.

Del proyecto de Convenio precitado destacan, entre otros, los siguientes puntos, que consisten en actividades que quedarían a cargo del gobierno del estado, por conducto de la Comisión Estatal del Agua (Órgano desconcentrado):

\section{- Formular la propuesta de la programación hídrica en la cuenca;}

\footnotetext{
22 Resultado del Proyecto realizado con Fondos Mixtos CONACYT-GOBIERNO DEL ESTADO DE SONORA Clave: Son-2004-C01-033 "Estudio de las alternativas de convenio federación - estado de sonora que regulen la administración conjunta de aguas nacionales"( Responsable técnico: Adria Velia González Beltrones), a celebrase entre el ejecutivo federal, a través de la Secretaría de Medio Ambiente y Recursos Naturales (SEMARNAT); la Comisión Nacional del Agua, órgano desconcentrado de la (SEMARNAT) y el gobierno del estado libre y soberano de Sonora.

${ }^{23}$ La Cuenca del Río Sonora cuenta con una extensión territorial de $28325 \mathrm{~km} 2$, que corresponde a 15 por ciento de la superficie estatal. En ella quedan comprendidos, en su totalidad, 11 municipios y 14 tienen parcialmente su territorio en dicha cuenca. De la población del estado, 31 por ciento se localiza en ésta, así como 39 por ciento de la población económicamente activa. De las cuencas existentes en el estado, la extensión total de aquélla se encuentra en el estado de Sonora y de todas ellas es la que presenta el mayor estrés hídrico. Su disponibilidad media por habitante al año es de $1183 \mathrm{m3}$, inferior al resto de las cuencas y al promedio estatal. En la parte baja y media de la cuenca se padece un proceso de erosión con grado de intensidad de baja a media, que se manifiesta en la pérdida promedio de suelo de 2.06 toneladas por hectárea al año, lo que a su vez propicia, por el arrastre de los sedimentos después de las avenidas, que los cauces de los ríos y arroyos queden con importantes grados de azolve y con la proliferación de vegetación que provoca inundaciones y anegamiento en las partes bajas. En la cuenca se usan en promedio 1020 millones de $\mathrm{m} 3$ al año y se calcula que sólo 800 millones son renovables (suma de agua superficial y agua subterránea), existiendo una sobreexplotación anual de 200 millones de $\mathrm{m} 3$.
} 
- Administrar los bienes públicos inherentes a la explotación, uso y aprovechamiento de aguas nacionales en el Estado;

- Expedir títulos de asignación y concesión de aguas nacionales;

- Conciliar y, en su caso, fungir a petición de los usuarios, como árbitro en la solución de conflictos relacionados con el agua y sus bienes públicos inherentes;

- Realizar estudios de disponibilidad, técnicos, sobre los usos de aguas nacionales, así como el monitoreo, prospección, evaluación, simulación y manejo de las mismas;

- Operar el Sistema Financiero del Agua;

- Determinar, liquidar, cobrar, recaudar y fiscalizar las contribuciones y aprovechamientos en materia de aguas nacionales y sus bienes inherentes;

- Participar en el Sistema de Información Hidroclimatológica y el Banco de datos, a tiempo real o histórico;

- Instrumentar y operar las redes de monitoreo de niveles y calidad de las aguas subterráneas;

- Verificar, inspeccionar y comprobar el cumplimiento de obligaciones previstas en la Ley de Aguas Nacionales y resolver los procedimientos administrativos correspondientes, así como calificar las infracciones e imponer sanciones administrativas;

- Ser depositario de la fe pública registral en materia de las aguas nacionales y sus bienes públicos y llevar el Registro Público de Derechos de Agua;

- Someter a la consideración del Ejecutivo Federal los proyectos de declaratorias, decretos, reglamentos y acuerdos de zonas reglamentadas de veda y de reserva de aguas nacionales, así como de acuerdos para el establecimiento de distritos de riego;

- Regular la transmisión de derechos de aguas nacionales.

Por otro lado cabe precisar que:

14) El precitado Convenio además contempla que, la CNA concurra con el gobierno del estado de Sonora, proporcionando asesoría técnica y capacitación, así como los recursos provenientes de los programas Alianza para el Campo y Agua Potable y Alcantarillado en Zonas Urbanas, con base en la disponibilidad y Reglas de Operación respectivas.

15) Asimismo, el multicitado Convenio establece el compromiso del gobierno del Estado de Sonora de cumplir con los criterios de calidad que determine la CNA y, al cabo de un año, obtener el certificado de calidad ISO 9000:2000 o la que se encuentre en vigor al momento de iniciar el proceso de certificación correspondiente, así como a presentar un informe periódico de las actividades realizadas en la ejecución de las funciones, programas y acuerdos que se deriven del convenio, sin perjuicio de la evaluación periódica que ambas partes llevarán a cabo acerca de los resultados de las acciones comprometidas, mediante el establecimiento conjunto de indicadores.

16) A dos años de distancia de la elaboración y propuesta del citado proyecto de convenio de descentralización de facultades en materia de gestión del vital líquido en la Cuenca del Río Sonora entre la Federación y el gobierno del Estado de Sonora la situación poco o nada ha cambiado, ${ }^{24}$ lo que confirma la urgencia de dejar de lado las formas tradicionales de administración pública que habiendo llegado a su límite, enfrentan una tendencia mundial generalizada que expresa el cuestionamiento y reclamo de la sociedad y que obliga a cambiar hacia formas mas incluyentes de gobernar. Lo que ha dado lugar a reflexiones y conceptos nuevos que encuentran un eje en torno a la idea de "gobernación" o "gobernanza" que marca el hecho de que la gestión pública no se agota en el ámbito gubernamental sino

\footnotetext{
${ }^{24}$ pues una vez mas prevalece, además de la falta de voluntad política, la ausencia de participación de la población directamente afectada por la falta a su vez, de conciencia de la importancia de: a)exigir de las autoridades competentes responsabilidad en su actuación en relación a la gestión del agua b) demandar espacios de participación a través de la inclusión de mecanismos efectivos y sencillos en los ordenamientos jurídicos conducentes para que los afectados puedan potenciar su actuación en forma individual u organizada de manera eficiente y corresponsable y al mismo tiempo c) poder exigir cuentas a las autoridades en su manejo; Revista Jurídica del Departamento de Derecho Academia de Derecho Administrativo Tercera Época. Año 2. No 2. Vol. 1.Enero-Junio 2010
} 
por el contrario, la complejidad de los problemas exige crecientes y ampliados espacios y mecanismos para una participación protagónica de otros agentes ${ }^{25}$. El cambio en la actuación de la administración impulsado desde la esfera municipal por la ciudadanía y respaldado por las relaciones intergubernamentales municipio-entidad federativa - federación. ${ }^{26}$

\section{A manera de Conclusiones}

En definitiva, una decisión de esta naturaleza requiere de voluntad política y una verdadera y constructiva discusión, con una agenda acordada entre gobiernos (local y federal) y la participación ${ }^{27}$ de las empresas privadas y las organizaciones de la sociedad civil involucradas en el tema del agua (gobernanza). Voluntad política que defina y traduzca en acciones concretas el discurso descentralizador del Estado. En primer término, para definir los límites de la descentralización y en segundo, para convenir de forma clara las responsabilidades relacionadas con la gestión del agua y recursos presupuestales asignables al efecto. Desafortunadamente como se menciona párrafo arriba, a la fecha no se ha concretado la voluntad política y la firma de conformidad del multicitado Convenio, tendrá tal vez que esperar a que lleguen los nuevos funcionarios locales que reemplazarán (Septiembre de 2009) a los hoy en turno y que logren influir en el sentir de los funcionarios federales al respecto . 0 quizás esperar a que la cuestión del agua se politice de manera tal que "las rivalidades emergentes en relación al agua entre los gobiernos locales y el federal, entre diferentes sectores de actividad, y entre zonas rurales y urbanas" obstaculicen primeramente la seguridad local seguida de la seguridad regional y consecuentemente la seguridad mundial, pues acorde a lo señalado por la ONU en el Informe sobre Desarrollo Humano (1994):

"Al hablar de seguridad ciudadana o seguridad pública se hace alusión a una dimensión más amplia que la mera supervivencia física. La seguridad es una creación cultural que hoy día implica una forma igualitaria (no jerárquica) de sociabilidad, un ámbito compartido libremente por todos. Esta forma de trato civilizado representa el fundamento para que cada persona pueda desplegar su subjetividad en interacción con los demás. De esta manera, frente a los hechos que afectan la seguridad de los ciudadanos está en juego no sólo la vida de la persona individual, sino igualmente la de la sociedad." Por lo que cabe preguntar

¿A quién corresponde constatar que las autoridades (locales y federales), particulares y sociedad civil efectivamente se responsabilicen de cada una de las funciones relacionadas con la gestión del agua? ¿Cuál es el margen de participación óptimo que le corresponde a cada uno en dicho rubro? La respuesta se dará en la medida de la efectiva cooperación y coordinación entre los agentes involucrados, evidenciada en el beneficio individual y colectivo obtenido.

\footnotetext{
${ }^{25}$ Carabias, Landa Rosalía, Collado Jaime y Martínez Polioptro "Agua, Medio Ambiente y Sociedad", México UNAM, CM, Fun. Gonzalo Río Arronte y otros : pp122.

${ }^{26}$ González Beltrones Adria Velia. ),"Las relaciones intergubernamentales y la participación ciudadana en la gestión integral del agua",en "Régimen Jurídico del Agua: Culturas y Sistemas Jurídicos Comparados, Fernández Ruiz Jorge y Santiago Sánchez Javier Ed UNAM, México.

${ }^{27}$ Parafraseando a Bernardo Kliksberg "A través de la participación se puede desencadenar círculos virtuosos: más participación puede llevar a políticas públicas más sensibles socialmente, y a inversiones sociales mayores .La participación es deseable en cualquier contexto histórico, pero en el caso particular de América Latina es clave para que la gente recupere su voz, las sociedades sean más equilibradas y se creen condiciones para enfrentar los intolerables niveles de indigencia actuales."
} 
Bibliografía

[1]. Aboites, Luis: El agua de la nación. Una historia política de México (1888-1946). México: Ed. Centro de Investigaciones y Estudios Superiores de Antropología Social 1998

[2]. Acosta Romero, Miguel: Teoría General del Derecho Administrativo. México: Editorial Porrúa 2004

[3]. Becerra Pérez Mariana, Jaime Sainz Santamaría y Carlos Muñoz Piña: Los conflictos por agua en México. Diagnóstico y análisis. México: Gestión y Política Pública 2006. Vol. XV (1): 111

[4]. Carabias Julia,Landa Rosalía,Collado Jaime y Martínez Polioptro: Agua, Medio Ambiente y Sociedad". México: UNAM, CM, Fun. Gonzalo Río Arronte 2006

[5]. Comisión Estatal del Agua: Reunión del Consejo de Cuenca del Río Sonora,14 de marzo. “Intervención del ingeniero José Luis Jardines". Director de la Comisión Estatal del Agua. México: 2006

[6]. Comisión Nacional del Agua: Lo que se dice del Agua. México: Ed. CNA 2005

[7]. Delgadillo Martínez Luis Humberto, Lucero Espinoza, Manuel: “Compendio de Derecho Administrativo". México: Ed. Porrúa 2003

[8]. Fraga, Gabino: Derecho Administrativo. México: Editorial Porrúa 2006

[9]. González Beltrones Adria Velia: Las relaciones intergubernamentales y la participación ciudadana en la gestión integral del agua, en Régimen Jurídico del Agua. Culturas y Sistemas Jurídicos Comparados,

[10]. Fernández Ruiz Jorge y Santiago Sánchez Javier.México: Ed. UNAM 2006

[11]. GWP "Manejo integrado de recursos hídricos", TAC background paper no.4 Suecia: Global Water Partnership 2000

[12]. Instituto de Investigaciones Jurídicas, Universidad Nacional Autónoma de México: "Diccionario Jurídico Mexicano. México: Ed. UNAM 1993.

[13]. Kliksberg Bernardo ¿Cómo avanzar la participación en América Latina, el continente más desigual? Santo Domingo, República Dominicana: Anotaciones estratégicas XII Congreso Internacional del CLAD sobre la Reforma del Estado y de la Administración Pública, 30 de octubre - 2 de noviembre 2007

[14]. Lanz Cárdenas, José Trinidad. Legislación de aguas en México: Villahermosa Tabasco México: Consejo Editorial del Estado de Tabasco 1982

[15]. Moreno, José Luis. Por abajo del agua. Sobreexplotación y agotamiento del acuífero de la Costa de Hermosillo, 1945-2005. México: El Colegio de Sonora. 2006

[16]. Secretaría de Hacienda y Crédito Público. Antología de la planeación en México. Tomo 5. México: Fondo de Cultura Económica 1985

[17]. Serra Rojas, Andrés “Derecho Administrativo: México: Editorial Porrúa 1994

[18]. Sánchez Meza Juan Jaime ¿Se ha descentralizado la gestión del agua en México?, México: Tesina mimeo 2005

Revista Jurídica del Departamento de Derecho

Academia de Derecho Administrativo

Tercera Época. Año 2. No 2. Vol. 1.Enero-Junio 2010 
Legislación

Constitución Política de los Estados Unidos Mexicanos. México: Ed. Porrúa.2005

Ley de Aguas Nacionales y su Reglamento. México: Subdirección Jurídica CNA.2004

Ley de Aguas Nacionales.México: 1992

Webgrafía

http://www.ecoportal.net/content/view/full/84833 